\title{
Expression of CD105 (Endoglin) in Hepatocellular Carcinoma and Correlation with Intrahepatic Metastasis: Analysis Using Tissue Microarrays and Comparison with Other Endothelial Marker
}

\author{
Li Hou ${ }^{1}$, Daisuke Mori ${ }^{2}$, Yukari Takase ${ }^{1}$, Rahmawati Minhajat ${ }^{1}$, Fumio Yamasaki ${ }^{1}$, Kohji Miyazaki ${ }^{3}$ \\ and Osamu Tokunaga ${ }^{*}, 1$
}

Departments of ${ }^{1}$ Pathology and Biodefense and ${ }^{3}$ Surgery, Faculty of Medicine, Saga University, Saga, Japan

${ }^{2}$ Clinical Laboratory, Pathology Division, Saga Prefectural Hospital Koseikan, Saga, Japan

\begin{abstract}
Neovascularization provides the route for nutrient supply to the tumor and the conduit for tumor cells to be shed into the circulation. CD31 is a pan-endothelial cell marker and CD105 is an active endothelial cell marker, but whether there is a link between CD105 expression and metastasis in Hepatocellular carcinoma (HCC) still remains unclear. A tissue microarray containing $38 \mathrm{HCCs}$ and adjacent non-tumorous liver tissue samples was constructed. The microvessel density (MVD) of CD31, CD105, vWF and the expression of PCNA, VEGF were investigated in a HCC tissue microarray by immunohistochemistry. There was a significant difference between the score of MVD-CD31 in HCC (48.5 $\pm 29.7)$ and non-tumorous liver tissue $(24.2 \pm 22.3$, P<0.01). The mean score of MVD-CD31 was higher in HCCs with high PCNA expression $(68.4 \pm 37.0)$ than in HCCs with low PCNA expression $(37.9 \pm 30.9, \mathrm{P}=0.012)$. MVD-CD105 and VEGF expression were significantly higher in HCC with intrahepatic metastasis $(\mathrm{P}<0.01)$. Multivariate analysis confirmed that MVD- CD105 but not MVD-CD31 was an independent contributing factor to the intrahepatic metastasis. In conlusions, MVD-CD105 expression is associated with intrahepatic metastasis of HCC. Because CD105 is expressed in the activated endothelial cells of the newly formed blood vessels, neovascularization is important in the metastasis of HCC.
\end{abstract}

\section{INTRODUCTION}

Hepatocellular carcinoma (HCC) is one of the most common cancers and is one of the leading causes of cancer death in Japan [1]. It is a tumor characterized by a propensity for vascular invasion and a high metastatic potential [2]. Angiogenesis is a prerequisite for tumor growth and metastasis [3]. Neovascularization provides not only the route for nutrient supply to the tumor but also the conduit for tumor cells to be shed into the circulation [4]. Newly formed capillaries have leaky basement membranes, making them more accessible to tumor cells than mature vessels. It has been demonstrated that increasing density of newly proliferating microvessels in growing tumors was correlated closely with increasing number of tumor cells shed into the bloodstream [5]. CD105 (endoglin) is a component of the transforming growth factor beta (TGF- $\beta$ ) receptor complex as it binds TGF- $\beta 1$ and TGF- $\beta 3$ with high affinity. CD105 has been reported as expressed by endothelial cells of proliferating capillaries [6]. However there are few reports on the expression of CD105 in hepatocellular carcinoma $[7,8]$. The expression pattern of CD105 and a link between CD105 expressing capillaries and metastasis in HCC still remain unclear. Tissue microarray is a method which can detect the protein expression of a large number of samples simultaneously [9]. Therefore, we conducted a prospective study using

*Address correspondence to this author at the Department of Pathology and Biodefense, Faculty of Medicine, Saga University, Saga 849-8501, Japan; Tel: 81-952-34-2230; Fax: 81-952-34-2055;

E-mail: tokunao@cc.saga-u.ac.jp tissue microarray methodology to evaluate the expression of CD105 in 38 resected HCCs.

\section{MATERIALS AND METHODS}

\section{Patients and Tissue Samples}

Thirty eight patients with curative resection of HCC were recruited into this prospective study at Saga University Hospital from 1999 to 2004 under the guideline of the Ethical Committee for Human Study, Saga University School of Medicine. The average age of patients was 64 years, ranging in age from 43 to 82 years. There were 7 women and 31 men. The average tumor size was $6.6 \mathrm{~cm}$ with 13 tumors less than $3 \mathrm{~cm}$. Among the 38 patients with HCC, 27 had hepatitis $\mathrm{C}$ infection and 6 had hepatitis $\mathrm{B}$ infection. The fresh tissue specimens were fixed in $10 \%$ buffered formalin and embedded in paraffin. Intrahepatic metastasis (IM) was diagnosed as follows: near the main tumor, much smaller than main tumor and with the same histology type as the main tumor. During this study, we found that the number of surgically resected HCC cases larger than $3 \mathrm{~cm}$ in diameter was small and we added further 24 cases to match the number of HCC with large size for comparison by courtesy of our affiliated hospital Koseikan.

\section{Construction of Tissue Microarrays of HCC}

Tissue microarray was constructed using a Tissue Arrayer (Beecher Instruments Inc., Sun Prairie, WI, USA), providing microsections of $2 \mathrm{~mm}$ in diameter (Fig. 1). The appropriate tumor areas were selected on HE paraffin sections. Three areas which were located in the central and pe- 


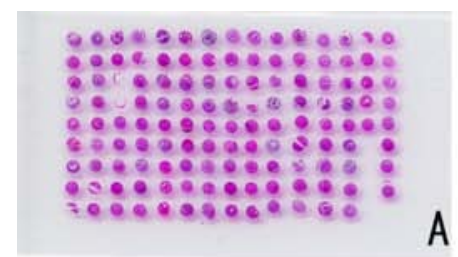

\section{A}
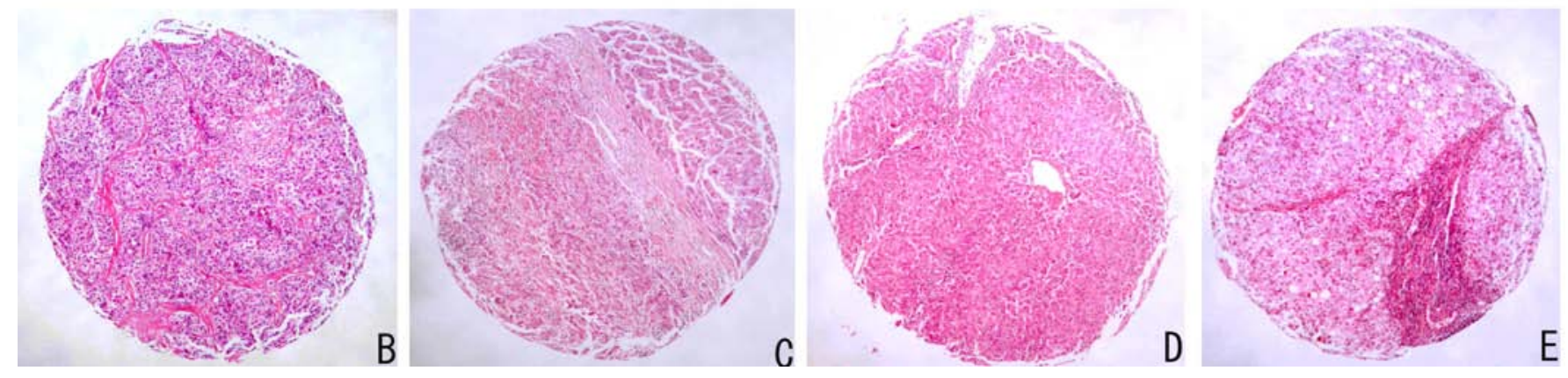

Fig. (1). The tissue microarray of HCC. (A) Slide of H.E. staining. (B-E) Representative tissue samples. (B) HCC. (C) Transitional zone of HCC. (D) Chronic hepatitis. (E) Cirrhosis.

ripheral part of the cancer, and non-cancerous liver tissue were selected in each sample. Cores were punched out from donor blocks and placed in recipient blocks. An array block of 119 cores was derived from normal liver tissue $(n=5)$, center part of the cancer $(n=38)$, peripheral part of the cancer $(\mathrm{n}=38)$ and non-cancerous liver tissue $(\mathrm{n}=38)$. The array blocks were then incubated for $30 \mathrm{~min}$ at $37^{\circ} \mathrm{C}$ to improve adhesion between the cores and the recipient paraffin block. Immunohistochemical studies were performed on $4 \mu \mathrm{m}$-thick paraffin sections.

\section{Double-Immunofluorescence Staining}

Double-immunofluorescence staining was performed following a previously reported method [10]. Briefly, the tissue array slides were deparaffinized and soaked in $0.01 \mathrm{M}$ citrate buffer, $\mathrm{pH} 6.0$, at $90^{\circ} \mathrm{C}$ for $40 \mathrm{~min}$ for antigen retrieval. The primary murine monoclonal antibody CD31, and then rhodamine-labeled secondary rabbit polyclonal antibody against murine $\operatorname{IgG}$ were allowed to react. After inactivation of the first step of primary and secondary antibodies by heating at $90^{\circ} \mathrm{C}$ for $15 \mathrm{~min}$ in citrated buffer, the second immunoreaction was carried out with another primary murine monoclonal antibody, CD68, and then with FITC-labeled secondary rabbit polyclonal antibody. Rhodamine and FITClabeled samples were examined using a fluorescence microscope (Olympus BX60, Tokyo, Japan). To detect nonspecific-antibody binding, control sections were incubated with either normal murine or rabbit serum or phosphate-buffered saline instead of primary antibody. No staining was observed in these control samples.

\section{Immunohistochemical Staining}

Sections of tissue microarray were immunostained with human CD105, CD31, von Willebrand factor (vWF), proliferating cell nuclear antigen (PCNA), vascular endothelial growth factor (VEGF) monoclonal antibodies, respectively. Table 1 showed the details of antibody used in this research. The tissue sections were dewaxed, soaked in PBS (pH7.2), and then treated with $10 \%$ hydrogen peroxide to block endogenous peroxidase activity. Antigen retrieval was performed following a previously reported method [10]. The tissue microarray sections were then incubated with primary antibodies at $4^{\circ} \mathrm{C}$ over night. The negative control was obtained by substituting the primary antibodies for PBS. Intensity of immunostaining for CD31, CD105 and vWF was assessed at $\times 200$ magnification. The number of microvessels was counted from three areas and was expressed as microvessel density (MVD) on the average.

Table 1. Antibodies and Antigen Retrieval Methods

\begin{tabular}{|c|c|c|c|c|}
\hline Antibody & Clone & Pretreatment & Dilution & Company \\
\hline \hline CD31 & Mono & Proteinase K & $1: 20$ & Dako \\
\hline CD105 & Mono & MW-EDTA & $1: 50$ & Novocastra \\
\hline vWF & Mono & Proteinase K & $1: 100$ & Dako \\
\hline VEGF & Mono & MW-AC & $1: 100$ & Santa Cruz \\
\hline PCNA & Mono & MW-EDTA & $1: 50$ & Dako \\
\hline
\end{tabular}

Antigen retrieval method for immunohistochemistry: MW:microwave,

AC:citrate buffer, For immunofluorescence, see Materials and Methods.

The rate of PCNA-positive cancer cells was defined as the positively stained nuclei to the total cell count. The positive nuclei less than $1 \%$ was evaluated as $0,1-20 \%$ evaluated as $1,21-50 \%$ evaluated as 2 , over $50 \%$ evaluated as 3 . We regarded 2 and 3 as high expression of PCNA. The judgment of VEGF staining was adopted as the proper immunohistochemical score of the HCC on the basis of strength: 0 , negative; 1 , weak staining; 2 , moderarate staining; 3 , strong staining. We regarded $1-3$ as positive VEGF staining. In this study, the staining pattern of VEGF was diffuse.

All of the immunostaining scores were calculated by two pathologists in a blinded manner.

\section{Statistical Analysis}

The clinical and pathologic characteristics of the patients in relation to MVD of CD105, CD31, vWF and the expression of VEGF, PCNA were compared by the student's $t$ test and $\mathrm{x}^{2}$ test. SYSTAT 10.2 (Systat Software Inc., Chicago, 
IL, USA) was used. The $P$ value of less than 0.05 was considered to be significant. For Multivariate analysis, JMP Statistics program (SAS Institute, Cary, NC, USA) was used.

\section{RESULTS}

The Expression Pattern of CD31, vWF, CD105, PCNA and VEGF in HCC and Non-Tumorous Liver

CD31 was universally expressed in endothelial cells of newly formed sinusoid in HCC (Fig. 2A). In non-tumorous liver tissues, which were normal, cirrhotic or associated with chronic hepatitis, there was a limited staining at the portal area in the normal liver, and a sparse staining in the latter two (Fig. 2B).

The pattern of staining by anti-vWF was different from that by anti-CD31, with staining of mainly larger vessels in the fibrous tissue within the tumor, rather than the capillarylike sinuoids between cancer cells (Fig. 3A). CD105 was also expressed in endothelial cells of newly formed sinusoids in HCC (Fig. 3B). PCNA was expressed in the nuclei (Fig. 3C). VEGF was expressed mainly in the cytoplasm of HCC and non-tumorous liver tissues (Fig. 3D).
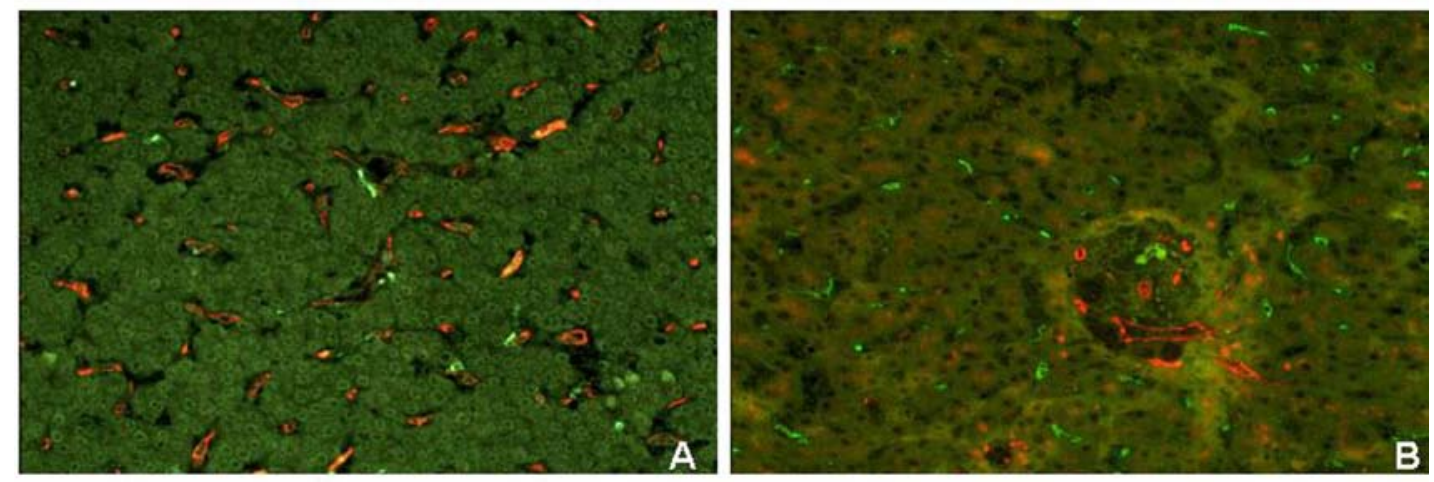

Fig. (2). CD31 expression in HCC and non-HCC liver tissue. (A) CD31 (red) was observed in endothelial cells of newly formed sinusoid in HCC. (B) CD31 was only positive in the vascular endothelial cells in portal area in non-HCC liver tissue. Green: CD68 positive kupffer's cells. $x 200$.
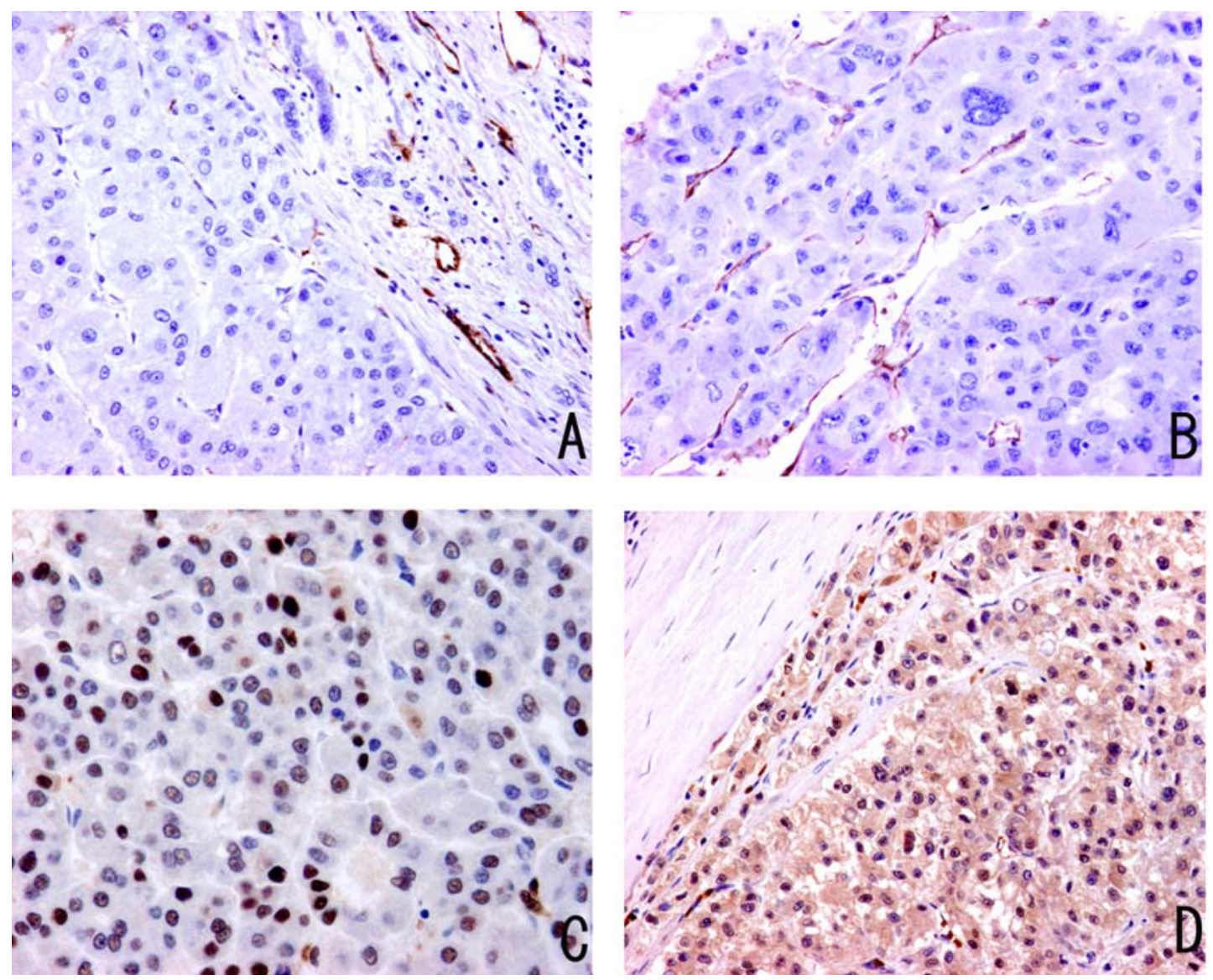

Fig. (3). The vWF, CD105, PCNA, and VEGF expression in HCC. (A) The vWF expression was observed in endothelial cells of larger vessels in the fibrous tissue of tumor. (B) CD105 expression was observed in endothelial cells of newly formed sinusoids in HCC. (C) PCNA expression was seen in nuclei of HCC cell. (D) VEGF expression was observed in HCC cell cytoplasm in a diffuse staining pattern. $\mathrm{x} 200$. 


\section{MVD in HCC and Non-Tumorous Liver}

The mean score of MVD-CD31 was $48.5 \pm 29.7$ in HCC, whereas the mean score of MVD-CD31 was $24.2 \pm 22.3$ in non-tumorous liver tissue (Fig. 4). There was a significant difference between the score of MVD-CD31 in HCC and non-tumorous liver tissue $(\mathrm{P}<0.01)$. The mean score of MVD-CD31 was higher in HCC with high PCNA expression $(68.4 \pm 37.0)$ than in HCCs with low PCNA expression (37.9 $\pm 30.9, \mathrm{P}=0.012$ ) (Fig. 5).

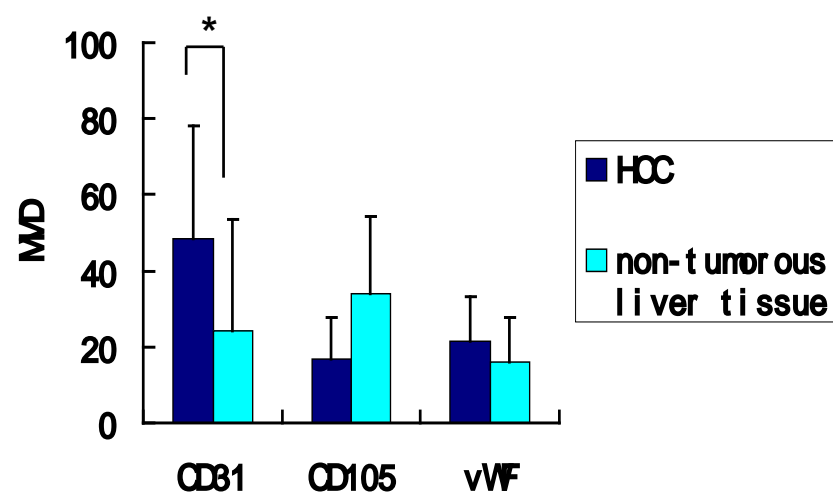

* $p$-value between groups $<0.01$

Fig. (4). Comparison of MVD in HCC and non-tumorous liver tissue. There was a significant difference on the score of MVDCD31 between HCC and non-tumorous liver tissue $(* \mathrm{P}<0.01)$. But there was no significant difference on the score of MVD-105 or vWF between HCC and non-tumorous liver tissue.

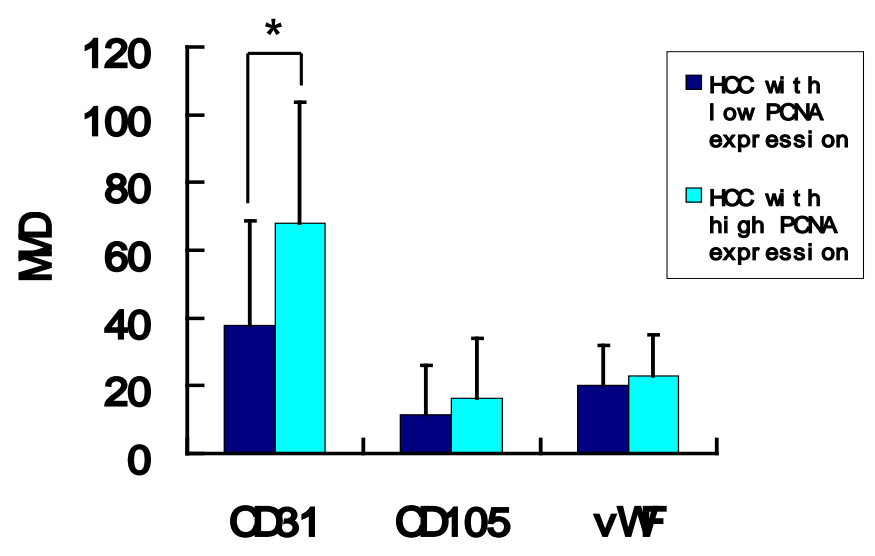

${ }^{*} p$-value between groups $=0.012$

Fig. (5). The relationship between MVD-CD31, -CD105, and -vWF and the expression of PCNA in HCC. The mean score of MVDCD31 was higher in HCCs with high PCNA expression than with low PCNA expression. * $\mathrm{P}=0.012$. There was no significant difference between the score of CD105 and vWF.
The MVD-CD105 was significantly lower than MVDCD31 in the same tissue. There was a diffuse staining pattern of CD105 in adjacent non-tumorous livers in some specimens. There was no significant difference between the score of MVD-105 or vWF in HCC and non-tumorous liver tissue.

Correlation Between MVD and Expression of PCNA and VEGF and Clinicopathological Parameters

The analysis of MVD-CD31, MVD-CD105, MVD-vWF in relation to various clinicopathological parameters is summarized in Table 2. Significantly higher MVD-CD105 was only associated with HCC with intrahepatic metastasis (IM) $(\mathrm{p}<0.01)$. Multivariate analysis showed that a high MVDCD105 was a significant $(\mathrm{p}=0.0214)$ and independent contributing factor to intrahepatic metastasis (IM, Table 3). Furthermore, in large HCCs (> 3cm) with IM, the MVD-CD105 was $27.09 \pm 18.35$, while in large $\mathrm{HCCs}$ without IM, the MVD-CD105 was $7.27 \pm 6.07$. It revealed that CD105 was significantly stronger expressed in HCC with IM even in large tumours (Fig. 6). No significant differences, however, were found between MVD-CD31 or MVD-vWF and each clinicopathological parameter such as gender, tumor size, venous invasion and IM.

Table 2. Relationship Between MVD of CD105, CD31, vWF and Clinicopathological Parameters in HCCs

\begin{tabular}{|c|c|c|c|}
\hline \multirow{2}{*}{ Variable } & \multicolumn{3}{|c|}{ Positive Microvessel Density } \\
\hline & MVD-CD105 & MVD-CD31 & MVD-vWF \\
\hline \multicolumn{4}{|l|}{ Sex } \\
\hline $\operatorname{Male}(\mathrm{n}=31)$ & $14.6 \pm 12.5$ & $56.5 \pm 35.5$ & $22.6 \pm 11.7$ \\
\hline Female $(\mathrm{n}=7)$ & $32.0 \pm 26.9$ & $32.0 \pm 36.6$ & $16.8 \pm 14.2$ \\
\hline \multicolumn{4}{|l|}{ Tumor Size } \\
\hline$\leq 3 \mathrm{~cm}(\mathrm{n}=13)$ & $14.4 \pm 12.5$ & $65.3 \pm 32.0$ & $22.8 \pm 8.0$ \\
\hline$>3 \mathrm{~cm}(\mathrm{n}=25)$ & $19.3 \pm 18.7$ & $49.6 \pm 37.1$ & $21.5 \pm 13.5$ \\
\hline \multicolumn{4}{|l|}{ Histology Type } \\
\hline Well(n=7) & $15.1 \pm 14.9$ & $45.2 \pm 32.3$ & $14.8 \pm 10.7$ \\
\hline $\operatorname{Moderate}(\mathrm{n}=27)$ & $15.9 \pm 14.1$ & $56.8 \pm 39.2$ & $22.4 \pm 12.6$ \\
\hline Poor $(n=4)$ & $35.5 \pm 14.1$ & $34.8 \pm 7.8$ & $26.8 \pm 8.3$ \\
\hline \multicolumn{4}{|l|}{$\mathrm{IM}$} \\
\hline With $(n=14)$ & $26.8 \pm 19.8^{*}$ & $66.6 \pm 39.4$ & $25.2 \pm 15.2$ \\
\hline Without $(n=24)$ & $11.9 \pm 11.1^{*}$ & $44.9 \pm 32.9$ & $19.7 \pm 9.9$ \\
\hline \multicolumn{4}{|l|}{ Vascular Invasion } \\
\hline With(n=18) & $18.2 \pm 17.4$ & $54.7 \pm 39.8$ & $22.7 \pm 15.4$ \\
\hline Without(n=20) & $17.4 \pm 17.3$ & $50.5 \pm 33.7$ & $20.6 \pm 8.2$ \\
\hline
\end{tabular}

There was no significant difference in the intensity of VEGF expression between the HCC cells and the nontumorous liver cells. However, VEGF was expressed in 92.3\% (12/13) of HCCs with IM and in $45.8 \%$ (11/24) of HCCs without IM. VEGF expression was significantly higher in HCC with IM $(\mathrm{p}<0.01)$. 


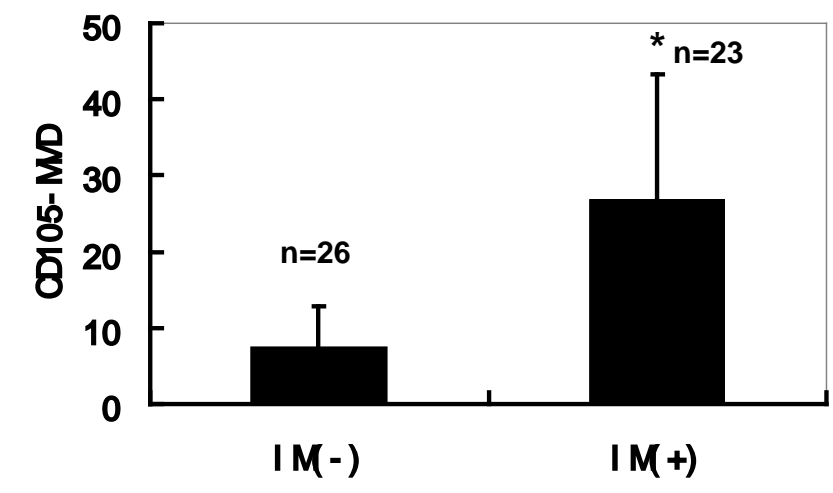

\section{${ }^{*} p$-value between groups $=0.0214$}

Fig. (6). MVD-CD105 in large HCCs (> 3cm) with or without intrahepatic metastasis (IM). MVD-CD105 is significantly higher in HCC with IM than those without IM. ${ }^{*} \mathrm{P}=0.0214$. Twenty five HCC cases larger than $3 \mathrm{~cm}$ were combined with 24 those cases from Koseikan Hospital.

Table 3. Multivariate Analysis of the Contributing Factors to the Intrahepatic Metastasis

\begin{tabular}{|l|l|l|}
\hline \multicolumn{1}{|c|}{ Factor } & F & P Value \\
\hline \hline Diameter & 2.07 & 0.5584 \\
\hline Histology type & 1.51 & 0.9590 \\
\hline Capsule invasion & 5.28 & 0.1527 \\
\hline Venous invasion & 2.15 & 0.9889 \\
\hline MVD-CD105 & 9.69 & 0.0214 \\
\hline MVD-CD31 & 2.21 & 0.5291 \\
\hline Age & 4.68 & 0.1964 \\
\hline
\end{tabular}

MVD: microvessel density.

\section{DISCUSSION}

The growth and metastasis of solid tumors are dependent on the formation of new blood vessels [11]. Angiogenesis is closely associated with the cancer development and facilitates tumor progression and metastasis [12]. Different from that in normal physiological condition, the balance of proangiogenesis and anti-angiogenesis is disturbed in tumor microenvironment, thus leading to abnormal vessel growth. Intratumoral microvessel density (IMVD) has been extensively investigated and found to be a useful prognostic marker in many cancers [13-15]. CD31 is a pan-endothelial cell marker, which is expressed in both of immature tumor blood vessels and mature blood vessels [16]. IMVD-CD31 may reflect the exact number of tumor blood vessels than other endothelial cell marker. We found that the mean score of MVD-CD31 in HCC was markedly higher than that in non-tumorous liver tissue. The frequency of MVD was in accordance with the results of previous studies on HCC [17]. And in non-tumorous liver, CD31 positive vessels existed on portal canal area. There was also a significant difference in the score of MVD-CD31 between HCC with different PCNA expression. These results suggested that increased angiogenesis prompted the proliferation of $\mathrm{HCC}$, which might be related to the carcinogenesis of HCC.

Metastasis is the most lethal attribute of malignant tumors. HCC often gives rise to IM, which would lead to failure of the cure. CD105 is a homodimeric membrane glycoprotein expressed on endothelial cells that can bind to TGF$\beta 1$ and $-\beta 3$. It is only expressed on active endothelial cells and consequently be able to reflect a neoangiogenesis in malignant tumors $[10,18]$. Neovascularization provides not only the route for nutrient supply to the tumor but also the conduit for tumor cells to be shed into the circulation because newly formed vessels are often absent of basement membrane [19]. Recent research has shown that CD105 is only weakly expressed in normal tissues, but it is strongly expressed in tumor endothelial cells [10, 20, 21]. CD105 has been demonstrated to be a good tumor angiogenesis marker in breast cancer [22], colorectal cancer [10, 23] and melanoma [24]. Higher expression and the superiority of CD105 over CD31 in active angiogenesis in HCC were recognized by many investigators $[7,8,25,26]$, but there are controversial opinions about its specificity in that the higher expression was not only present in microvessels in HCC but also in hepatic sinus endothelium in non-tumorous tissue with or without cirrhosis [26]. CD105 expression as a prognostic indicator is also controversial in microvessels of $\mathrm{HCC}[7,8]$. Benetti reported that TGF- $\beta 1$ promotes the migration of CD105 expressing HCC-derived endothelium [27]. But the direct link between CD105 expression and IM still remains unclear; we found that CD105 expression was higher in HCCs with IM than those without IM. Multivariate analysis showed that a high MVD-CD105 was a significant and independent contributing factor to intrahepatic metastasis. And CD105 was significantly expressed stronger in HCC with IM even in same size tumors. In our knowledge, we reported the close relationship between MVD-CD105 and IM for the first time. These results suggested that neovascularization might promote IM in HCC. Interestingly, we found a diffuse staining of CD105 in non-tumorous livers adjacent to HCC, which was previously reported [26]. It was not surprising because most of the HCC patients in this study were infected with hepatitis C virus (27/38) or B virus (6/38), which leads to chronic hepatitis or cirrhosis. The state of virus infection will induce a biological activity to the liver cell and enhance the CD105 expression.

Among the angiogenesis factors, VEGF is the most important one and a hot field of the study at present. A high serum level of VEGF is a predictor of poor outcome after resection of HCC [28]. We found that VEGF was expressed in $92.3 \%$ (12/13) of HCCs with IM and in $45.8 \%(11 / 24)$ of HCCs without IM. This result suggested that up-regulation of VEGF was related to IM of HCC.

In conclusion, we detected the MVD of CD31, CD105, vWF and the expression of PCNA, VEGF using a HCC tissue microarray. A higher MVD-CD105 was associated with IM of HCC. As CD105 is expressed on new blood vessels, neovascularization might be important in the metastasis of HCC. Further studies are needed to clarify the mechanisms. 


\section{ACKNOWLEDGEMENTS}

We thank Mr. Fumihiro Mutoh and Ms. Masami Shibaki for technical assistance.

\section{REFERENCES}

[1] Kudo M, Okanoue T. Japan Society of Hepatology. Management of hepatocellular carcinoma in Japan: consensus-based clinical practice manual proposed by the Japan Society of Hepatology. Oncology 2007; 72(Suppl 1): 2-15.

[2] Ribatti D, Vacca A, Nico B, Sansonno D, Dammacco F. Angiogenesis and anti-angiogenesis in hepatocellular carcinoma. Cancer Treat Rev 2006; 32: 437-44.

[3] Liotta LA, Stetler-Stevenson WG. Tumor invasion and metastasis: an imbalance of positive and negative regulation. Cancer Res 1991; 51(18 Suppl): 5054-59.

[4] Poon RT, Ng IO, Lau C, et al. Tumor microvessel density as a predictor of recurrence after resection of hepatocellular carcinoma: a prospective study. J Clin Oncol 2002; 20: 1775-85.

[5] Liotta L, Kleinerman J, Saidel G. Quantitative relationships of intravascular tumor cells, tumor vessels, and pulmonary metastases following tumor implantation. Cancer Res 1974; 34: 997-1004.

[6] Yoshitomi H, Kobayashi S, Ohtsuka M, et al. Specific expression of endoglin (CD105) in endothelial cells of intratumoral blood and lymphatic vessels in pancreatic cancer. Pancreas 2008; 37: 275-81.

[7] Ho JW, Poon RT, Sun CK, Xue WC, Fan ST. Clinicopathological and prognostic implications of endoglin (CD105) expression in hepatocellular carcinoma and its adjacent non-tumorous liver. World J Gastroenterol 2005; 11: 176-81.

[8] Yang LY, Lu WQ, Huang GW, Wang W. Correlation between CD105 expression and postoperative recurrence and metastasis of hepatocellular carcinoma. BMC Cancer 2006; 6: 110.

[9] Chan KL, Guan XY, Ng IO. High-throughput tissue microarray analysis of c-myc activation in chronic liver diseases and hepatocellular carcinoma. Hum Pathol 2004; 35: 1324-31.

[10] Minhajat R, Mori D, Yamasaki F, Sugita Y, Satoh T, Tokunaga O. Endoglin (CD105) expression in angiogenesis of colon cancer: analysis using tissue microarrays and comparison with other endothelial markers. Virchows Arch 2006; 448: 127-34.

[11] Folkman J. Angiogenesis in cancer, vascular, rheumatoid, and other disease. Nat Med 1995; 1: 27-31.

[12] Folkman J, Browder T, Palmblad J. Angiogenesis research: guidelines for translation to clinical application. Thromb Haemost 2001; 86: 23-33.

[13] Mineo TC, Ambrogi V, Baldi A, et al. Prognostic impact of VEGF, CD31, CD34, and CD105 expression and tumourvessel invasion after radical surgery for IB-IIA non-small cell lung cancer. J Clin Pathol 2004; 57: 591-7.

[14] Uzzan B, Nicolas P, Cucherat M, Perret GY. Microvessel density as a prognostic factor in women with breast cancer: a systematic review of the literature and meta-analysis. Cancer Res 2004; 64: 2941-55.
[15] Bialas M, Okon K, Czopek J. Assessing microvessel density in gastric carcinoma: a comparison of three markers. Pol J Pathol 2003; 54: 249-52.

[16] Sumpio BE, Yun S, Cordova AC, et al. MAPKs (ERK1/2, p38) and AKT can be phosphorylated by shear stress independently of platelet endothelial cell adhesion molecule-1(CD31) in vascular endothelial cells. J Biol Chem 2005; 280: 11185-91.

[17] Messerini L, Novelli L, Comin CE. Microvessel density and clinicopathological characteristics in hepatitis $\mathrm{C}$ virus and hepatitis B virus related hepatocellular carcinoma. J Clin Pathol 2004; 57: 86771.

[18] Miller DW, Graulich W, Karges B, et al. Elevated expression of endoglin, a component of the TGF-beta-receptor complex, correlates with proliferation of tumor endothelial cells. Int J Cancer 1999; 81: 568-72.

[19] Nagy JA, Brown LF, Senger DR, et al. Pathogenesis of tumor stroma generation: a critical role for leaky blood vessels and fibrin deposition. Biochim Biophys Acta 1989; 948: 305-26.

[20] She X, Matsuno F, Harada N, Tsai H, Seon BK. Synergy between anti-endoglin (CD105) monoclonal antibodies and TGF-beta in suppression of growth of human endothelial cells. Int J Cancer 2004; 108: 251-7.

[21] Takahashi N, Haba A, Matsuno F, Seon BK. Antiangiogenic therapy of established tumors in human skin/severe combined immunodeficiency mouse chimeras by anti-endoglin (CD105) monoclonal antibodies, and synergy between anti-endoglin antibody and cyclophosphamide. Cancer Res 2001; 61: 7846-54.

[22] Dales JP, Garcia S, Andrac L, et al. Prognostic significance of angiogenesis evaluated by CD105 expression compared to CD31 in 905 breast carcinomas: correlation with long-term patient outcome. Int J Oncol 2004; 24: 1197-204.

[23] Saad RS, Liu YL, Nathan G, Celebrezze J, Medich D, Silverman JF. Endoglin (CD105) and vascular endothelial growth factor as prognostic markers in colorectal cancer. Mod Pathol 2004; 17: 197203.

[24] Bodey B, Bodey B Jr, Siegel SE, Kaiser HE. Immunocyto- chemical detection of endoglin is indicative of angiogenesis in malignant melanoma. Anticancer Res 1998; 18(5A): 3621-8.

[25] Yao Y, Pan Y, Chen J, Sun X, Qiu Y, Ding Y. Endoglin (CD105) expression in angiogenesis of primary hepatocellular carcinomas: analysis using tissue microarrays and comparisons with CD34 and VEGF. Ann Clin Lab Sci 2007; 37: 39-48.

[26] Yu D, Zhuang L, Sun X, et al. Particular distribution and expression pattern of endoglin (CD105) in the liver of patients with hepatocellular carcinoma. BMC Cancer 2007; 7: 122.

[27] Benetti A, Berenzi A, Gambarotti M, et al. Transforming growth factor-beta1 and CD105 promote the migration of hepatocellular carcinoma-derived endothelium. Cancer Res 2008; 68: 8626-34.

[28] Kanematsu M, Osada S, Amaoka N, Goshima S, Kondo H, Moriyama N. Expression of vascular endothelial growth factor in Hepatocellular carcinoma and the surrounding liver: correlation with angiographically assisted CT. Abdom Imaging 2006; 31: 78-89.

Received: January 1, 2009

Revised: January 12, 2009

Accepted: January 19, 2009

(C) Hou et al.; Licensee Bentham Open.

This is an open access article licensed under the terms of the Creative Commons Attribution Non-Commercial License (http: //creativecommons.org/licenses/by-nc/ 3.0/) which permits unrestricted, non-commercial use, distribution and reproduction in any medium, provided the work is properly cited. 